\title{
The Development of Young Children's Understanding of Intentionality of Teaching and Theory of Mind, and its Relation to Their Understanding of Teaching Intention of an Actual Teaching Activity
}

Jeein Jeong

Interdisciplinary Studies in Human Development, Graduate School of Education, University of Pennsylvania, Philadelphia, United States

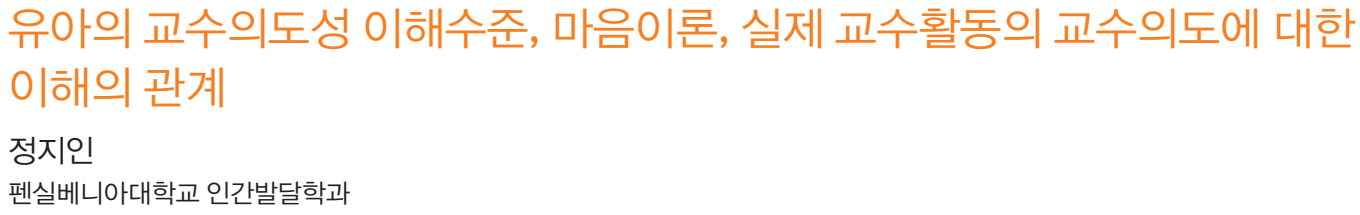

Objective: The current study intends to examine how young children understand intentionality of teaching with the theory of mind development, and how this understanding relates to their understanding of a teaching intention of an actual teaching activity.

Methods: The theory of mind of 90 children aged 3-5 years and their understanding of intentionality of teaching were assessed. Additionally, children were randomly assigned to experimental condition in which the teaching intention of an activity (memory game) was explicitly revealed, or control condition in which the intention was not stated. Afterwards, their understanding of the teaching intention of the game was measured. The development of understanding of intentionality of teaching, and its relation to their theory of mind were examined. Whether age and understanding of intentionality of teaching predicted children's understanding of the teaching intention of the game was also investigated.

Results: Along with the theory of mind development, children's understanding of intentionality of teaching also developed. Children's understanding of teaching intention of the game was related to their understanding of intentionality of teaching with age controlled. Children's recognition of the teaching intention of the game was predicted by understanding of the intentionality of teaching in the control condition, and it was predicted by both age and understanding of intentionality of teaching in the experimental condition.

Conclusion: With the development of theory of mind, children come to understand that teaching involves a goal, and this development plays an important role in their appreciation of an actual teaching intention of the activity.

Keywords: intentionality of teaching, theory of mind, understanding of teaching intention of activity

Corresponding Author: Jeein Jeong, Interdisciplinary Studies in Human Development, Graduate School of Education, University of Pennsylvania, 3700 Walnut Street., Philadelphia, PA 19104-6216, United States E-mail: jeongjee@gse.upenn.edu (c) The Korean Association of Child Studies

This is an Open Access article distributed under the terms of the Creative Commons Attribution Non-Commercial License (http:// creativecommons.org/licenses/by-nc/4.0) which permits unrestricted noncommercial use, distribution, and reproduction in any medium, provided the original work is properly cited. 


\section{서론}

유아들은 타인과의 상호작용을 통해 배우고 성장한다. 그중에 서도 누군가의 가르침, 즉 교수(teaching)를 통해 유아들은 다 양한 지식과 태도, 그리고 기술을 배우게 된다(Skerry, Lambert, Powell, \& Mcauliffe, 2013; Strauss, Ziv \& Stein, 2002). 유아들이 경험하는 교수의 형태는 다양하다. 때때로 교수의도가 명시되 는 직접적인 교수활동을 통해 배우기도 하지만, 때로는 교수 의도를 담고는 있으나 잘 드러나지 않는 교육적 게임 또는 탐 구활동을 통해 배우기도 한다. 그러나 유아들이 다양한 형태 의 가르침과 교수활동을 경험함에도 불구하고, 자신들이 경 험하는 교수활동에 대해 어떻게 지각하고 이해하는지에 대해 서는 충분한 연구가 이루어지지 못했다. 예를 들어, 교사가 새 로운 동물에 대해 가르쳐주기 위해 동물에 대한 게임을 준비 한 상황을 생각해보자. 유아들은 그 게임을 하는 의도를 어떻 게 받아들일까? 게임을 하는 과정에서 자연스럽게 교사의 교 수의도를 파악할 수 있을까? 교사가 새로운 동물에 대해 가르 쳐 준다는 교수의도를 설명해 준다면, 모든 연령의 유아들이 그 교수의도를 고려하면서 게임에 참여하게 될까? 이러한 질 문들은 유아들이 교수 상황에 대해 어떻게 지각하는지, 유아 들의 교수의도에 대한 인식이 교수자의 본래 의도와 항상 일 치하는지에 대해 생각해보게끔 한다. 본 연구에서는 마음이론 의 관점을 토대로 유아들이 교수활동에 대해, 특히 교수의도 성에 대해 어떻게 이해하는지, 그리고 이 이해의 발달이 실제 교수활동에 대한 인식과 어떤 관련이 있는지에 대해 살펴보고 자 한다.

사실 유아들이 지식의 변화를 수반하는 교수활동에 대해 이해하게 되는 과정에는 마음이론의 발달이 중요한 역할을 한 다(Davis-Unger \& Carlson, 2008; Strauss et al., 2002; Ziv \& Frye, 2004; Ziv, Solomon, \& Frye, 2008). 우선, 우리는 상대방이 지식 을 가지고 있지 않거나, 잘못된 지식을 가지고 있다고 믿을 때 에만 타인을 가르친다(Olson \& Bruner, 1996). 예를 들어, 한글 을 이미 아는 유아와 모르는 유아가 있다면, 교사는 전자보다 는 후자에게 한글을 가르치려고 할 것이다. 언제, 어떤 사람을 가르쳐야 하는지에 대해 유아들이 이해하기 위해서는, 지식을 비롯한 정신에 대한 기본적인 이해가 필요하다. 그리고 이 이 해는 마음이론의 발달과 밀접한 관련을 가진다.

교수활동은 또한 학습자의 지식이나 기술, 이해 등을 증진 하기 위한 교수자의 교수의도에서 비롯된다(Frye \& Ziv, 2005; Kruger \& Tomasello, 1996; Ziv et al., 2008). 교수활동의 교수의 도는 교수자를 통해 명시적으로 드러날 수도 있고, 경우에 따
라서는 직접적으로 드러나지 않을 수도 있다. 예를 들어, 서론 에서 소개된 예시에서와 같이, 새로운 동물에 대해 가르쳐주 겠다는 직접적인 안내가 없더라도 게임을 하는 과정을 통해 유아들은 자연스럽게 동물에 대해 배울 수 있다. 그렇지만 중 요한 것은 이 상황에서 게임이 새로운 동물에 대해 가르쳐주 려는 의도에서 출발한 교수활동이라는 것이다. 이러한 의도적 활동으로서의 교수에 대한 정의는 교수의도에서 비롯된 활동 과 교수의도가 없는 활동을 구분하게 해준다(Ziv et al., 2008). 예를 들어, 유아는 앞에 있는 친구가 종이접기 하는 것을 우연 히 보고, 따라하면서 종이접기를 배울 수 있다. 종이접기 하는 것을 가르쳐주려는 의도가 없는 경우에도, 친구의 행동을 보 면서 모방(imitation)을 통해 우연히 배울 수 있는 것이다. 그러 나 엄밀한 의미에서 이 모방 상황은 종이접기 하는 것을 의도 적으로 가르쳐주는 교수 상황과는 다르다고 볼 수 있다. 교수 상황에서는 친구의 의도를 고려하여 종이접기를 배우는 것이 사회적으로 기대되는 행동일 수 있다. 그러나 모방 상황에서 는 상대에게 종이접기를 가르쳐주려는 의도가 없었기 때문에, 굳이 종이접기를 배우는 것이 사회적으로 기대되는 상황은 아 니기 때문이다.

또한, 교수활동이 교수의도에서 출발한다는 이해는, 학습 결과와 관계없이 가르치려는 의도가 있었는지에 대해 정확하 게 판단하게 해준다(Ziv et al., 2008). 우리는 학습자에게 어떠 한 지식이나 기술을 가르치려고 노력하였음에도 불구하고, 학 습자가 그것을 잘 습득하지 못하는 상황을 종종 볼 수 있다. 그 러나 비록 학습자가 성공적으로 배우지는 못했다고 할지라도, 우리는 여전히 교수자가 그 학습자를 가르치려고 하였다고 판 단한다. 이러한 판단은 학습결과가 성공적인지 와는 무관하 게, 교수자의 교수의도를 파악할 수 있을 때에만 가능하다.

이러한 관점에서, 최근의 연구들은 유아들이 연령이 증가 함에 따라 주어진 상황이 교수의도에서 비롯되었는지 아닌지 에 대해 보다 정확하게 구분할 수 있게 된다는 것을 보고하였 다(Cavadel \& Frye, 2017; Ziv et al., 2008; Ziv, Solomon, Strauss, $\&$ Frye, 2016). 이들 연구에 따르면, 만 3, 4세 유아들은 학습 이 발생한 이유를 항상 교수자의 교수에서 찾는 경향이 있다 (Cavadel \& Frye, 2017; Ziv et al., 2008). 즉, 만 3, 4세 유아들은, 학습자가 모방을 통해 우연히 지식을 배우게 된 경우에도, 상 대방이 그 지식을 가르쳐주려고 하였기 때문에 배운 것이라고 생각한다는 것이다. 반면, 만 5세 이상의 유아들은 학습이 성 공적이었는지, 실패하였는지 와는 무관하게 어떤 상황에서 교 수자의 교수의도가 있었고, 어떤 상황에서는 없었는지에 대해 잘 구분할 수 있었다. 또한 만 5세 유아들은 게임이나 유도질 
문(교수자가 상대방이 잘 배웠는지 확인하기 위해 묻는 질문) 안에 지식을 가르치려는 교수의도가 숨어 있을 수 있다는 것 역시 개념적으로 이해하였다. 이러한 교수의도성에 대한 이해 는 유아들의 마음이론과도 정적 상관관계를 보였다. 종합하 면, 정신에 대한 이해인 마음이론이 발달함에 따라, 유아들이 교수활동을 학습자의 지식을 증진하기 위한 의도적인 활동으 로서 이해하게 된다는 것이다(Frye \& Ziv, 2005).

그렇지만, 마음이론과 관련한 연구들이 국내에서 다수 이 루어지기는 하였으나, 마음이론의 발달이 유아의 교수활동 에 대한 이해와 판단에 어떤 함의를 가지는지에 대한 접근 은 거의 이루어지지 않았다. 이전 연구들은 마음이론이 유아 들의 사회적 행동이나 적응(Oh, 2013; Chung, 2009), 언어 사 용(Song, 2004; N. Shin \& Kim, 2016), 그리고 놀이 행동(Park, 2006; E.-S. Shin, 2005) 등과 관련이 있음을 보여주었다. 예를 들어, 마음이론 수준이 높은 유아들은 유아교육기관에서도 사 회적 적응을 더 잘하며 $(\mathrm{Oh}, 2013)$, 또래관계에서도 사교성과 주도성이 높은 것으로 나타났다(Chung, 2009). 또한 마음이론 은 가장 놀이에서의 탈 맥락화 능력이나 언어적 표상, 실행기 능과도 정적 상관이 있었다(E.-S. Shin, 2005). 그러나 이러한 영역 외의 다른 발달 영역에서, 특히나 교수나 학습 상황에서 유아들의 마음이론이 어떻게 적용되는지에 대한 접근은 거의 이루어지지 않았다.

이러한 상황에서 국내에서는 H. Lee (2011)와 Yoon과 Kim (2012)이 Ziv 등(2008)이 고안한 도구를 번안하여, 유아들의 교수의도성에 대한 이해에 대해 측정하였고, 이 이해가 다른 발달 영역에 어떤 함의를 가질 수 있는지에 대해 다루었다. 교 수의도성에 대한 이해, 틀린 믿음 이해, 그리고 어휘력을 투입 한 모형은 만 5세 유아들의 학업 준비도를 예측하는 것으로 나 타났다(H. Lee, 2011). 또한 교수의도성 이해는 마음이론의 발 달과 유의한 상관이 있었으며, 교수의도성에 대해 잘 이해하 거나 마음이론 수준이 높은 유아들은 타인에게 새로운 게임 을 가르칠 때에도 게임의 규칙에 대해 더 잘 설명하고, 가르친 이후에도 본인이 그 사람을 어떻게 가르쳤는지에 대해 회상을 더 잘 하는 것으로 나타났다(Yoon \& Kim, 2012).

그러나 이러한 연구 외에는 마음이론의 발달에 따라 만 3세 에서 5세 사이에 교수의도성에 대한 이해가 어떻게 발달하는 지, 나아가 이 이해가 실제 교수활동에 대한 유아들의 인식에 어떤 영향을 주는지에 대한 접근이 거의 이루어지지 않았다. 지식, 믿음, 의도 등을 비롯한 정신에 대한 이해가 유아기에 폭 넓게 발달한다는 것과(Flavell, 2004), 유아들이 지식의 전달을 동반하는 교수활동을 끊임없이 경험한다는 점을 고려할 때,
이시기의 유아들이 교수 상황을 마음이론적 관점에서 어떻게 이해하기 시작하는지에 대한 질문은 발달적으로 중요한 함의 가 있다고 본다.

또한 연령이 증가함에 따라, 그리고 초등학교에 입학하게 됨에 따라, 유아들은 점점 더 다양한 형태의 교수활동을 경험 하게 된다. 이전 연구들은 교수 상황이 어떻게, 왜 발생하는지 에 대해 개념적으로 이해하는 것이 본인들이 경험하는 교수 활동과 학교 교육에 대해 이해하는데 기여한다고 제안하였다 (Cavadel \& Frye, 2017; Ziv \& Frye, 2004). 하지만 교수에 대한 이해, 특히 교수의도성에 대한 이해가 다양한 형태의 교수활 동을 왜 하는지에 대해 예측하고, 그 교수의도에 대해 인식하 는 것에 어떤 영향을 주는지에 대해서는 구체적으로 다루어지 지 않았다. 예를 들어, 유아들은 교수의도가 명시적으로 드러 나는 직접적인 교수활동을 경험하기도 하지만, 때때로 직접적 으로 드러나지 않는 암시적인 교수활동을 경험하기도 한다. 유아들은 직접적인 교수활동과 암시적인 교수활동의 교수의 도를 어떻게 기대하고 인식할까? 어떤 요인들이 활동의 교수 의도에 대한 유아의 이해에 영향을 주는 것일까? 이러한 질문 들은 교수활동의 목표를 어떻게 기대하고 인식하는지에 대해 유아의 관점에서 살펴보게끔 한다. 이에, 본 연구는 마음이론 적 관점을 토대로, 또한 교수가 학습자의 지식, 기술, 태도 등 을 증진하기 위한 의도에서 비롯된 활동(Frye \& $\mathrm{Ziv}, 2005)$ 이 라는 정의에 기반을 두고, 다음의 연구문제들에 대해 다루고 자 한다.

\section{연구문제 1}

유아들의 교수의도성에 대한 이해수준에는 연령별 차이가 있 는가?

\section{연구문제 2}

교수의도성에 대한 이해의 발달은 마음이론과 관계가 있는가?

\section{연구문제 3}

실제 교수활동의 교수의도에 대한 이해는 마음이론, 교수의도 성 이해수준, 연령, 교수의도에 대한 안내가 있는지의 여부에 따라 어떻게 달라지는가?

3-1. 활동의 교수의도에 대한 유아의 기대나 인식은 마음 이론과 교수의도성 이해 수준과 각각 관련이 있는가?

3-2. 활동의 교수의도에 대한 안내 유무에 따라, 교수의도 
성 이해수준과 유아의 연령이 실제 활동의 교수의도에 대 한 인식을 예측하는지의 여부가 달라지는가?

\section{연구방법}

\section{연구대상}

본 연구는 서울특별시에 있는 사립유치원과 공립어린이집에 재원중인 유아들을 대상으로 진행되었다. 유치원과 어린이집 을 포함하여 전체 8 개 학급에 연구에 대한 안내가 포함된 가정 통신문을 배부하였고, 이후 학부모가 동의한 유아들에 한해서 면접을 진행하였다. 최종적으로는 만 3세 28명(남아 13명, 여 아 15명, 3.30 3.90세, $M=3.65$ 세, $S D=.18$ ), 만 4세 28명(남 아 13명, 여아 15 명, 4.00 4.90세, $M=4.62, S D=.24$ ), 만 5세 34 명(남아 15 명, 여아 19 명, 5.00 5.90세. $M=5.50, S D=.27$ ) 이 참여하였다.

\section{연구도구}

본 연구에서는 유아들의 교수의도성 이해수준, 마음이론, 그 리고 실제 교수활동으로 사용된 메모리 게임을 한 의도에 대 해 유아들이 어떻게 이해하는지에 대해 측정하였다. 모든 측 정은 유아와의 일대일 면접을 통해 이루어졌으며, 각 도구에 대해 살펴보면 다음과 같다.

\section{교수의도성 이해수준}

유아들의 교수의도성 이해수준은 Ziv 등(2008)이 고안한 도 구를 Yoon과 Kim (2008)이 번안하여 제작한 그림 검사 과제를 사용하여 측정하였다. 본 연구에서는 12 개의 그림 검사 과제 중에서, 일반적인 의도에 대해 묻는 2 개의 과제를 제외하고, 교수의도성에 대한 이해를 측정하는 10 개의 과제를 사용하였 다. 10 개 중 8 개의 과제에서는, 그림을 통해 이야기 속의 어린 이가 교수 또는 모방을 통해 다른 등장인물로부터 지식을 배 우던지, 부분적으로 배우던지, 배우지 못하던지, 또는 학습결 과에 대한 정보가 주어지지 않는 상황들에 대해 들려주었다. 즉, 8 개의 이야기들은 등장인물의 교수의도가 있었는지(교수) 또는 없었는지(모방)에 따라, 그리고 학습결과가 성공적이었 는지, 부분적으로 성공이었는지, 실패였는지, 또는 결과에 대 한 정보가 주어지지 않았는지에 따라, 2(의도) $\times 4$ (결과)의 총
8가지 조합으로 설계되어 있었다(성공한 교수, 결과 미상인 교수, 부분적 성공인 교수, 실패한 교수, 성공적 모방, 결과 미 상인 모방, 부분적 성공인 모방, 실패한 모방). 각 이야기를 들 려준 다음에는, 유아들에게 이야기 속의 등장인물이 교수의도 를 가지고 있었는지 아닌지를 양자택일의 방식으로(예: "재윤 이는 민기를 가르쳐주려고 하였니? 아니면 가르쳐주려고 하 지 않았니?”) 물어보았다. 교수 상황에서는 학습결과가 성공 적이었는지 와는 관계없이 등장인물이 가르쳐주려고 하였다 고 대답한 경우에 1 점을 주었다. 반면, 모방 상황에서는 학습 결과와는 관계없이 등장인물에게 교수의도가 없었다고 대답 한 경우에 1점을 주었다.

10 개 중 나머지 2 개의 과제에서는, 교수자와 학습자가 교 육적 게임을 하는 상황(숨은 의도 게임)과 교수자가 학습자에 게 유도 질문을 하는 상황(숨은 의도 질문)을 그림을 통해 각 각 보여준 후, 유아가 교수자의 숨겨진 교수의도에 대해 이해 하는지에 대해 양자택일의 방식으로 질문하였다(예: “시연이 가 숫자게임을 왜 했을까? 재영이하고 놀고 싶어서 했을까? 아 니면 숫자를 가르쳐주려고 하였을까?”). 숨은 의도 게임에서 는 교수자가 게임을 하는 의도가 단순히 놀기 위한 것이 아니 라 숫자를 가르쳐주기 위해서라고 대답한 경우에 1점, 숨은 의 도 질문에서는 교수자의 의도가 모르는 것을 물어보기 위해서 가 아니라 학습자의 지식 상태를 확인하기 위해서라고 대답한 경우 1 점을 주었다. 따라서 교수의도 이해수준의 총점은 0-10 점이 되었다.

$$
\text { 마음이론 }
$$

유아들의 마음이론은 Gopnik과 Astington (1988)이 고안한 내 용 교체 과제를 사용하여 측정하였다. 색종이가 들어있는 반 창고 상자와 돌처럼 생긴 스폰지의 실체를 확인 한 후, 유아에 게 표상 변화 이해(예: 상자를 열기 전에 무엇이 들어있을 것 이라고 생각했었는지), 거짓 믿음 이해(예: 상자를 열어보지 않은 친구는 안에 무엇이 들어있을 것이라고 생각할지), 그리 고 외양 실제 구분(예: 겉으로 보기에는 무엇이 들어있을 것처 럼 보이는지, 실제로는 무엇이 들어있는지)에 대해 질문 하였 다. 표상 변화 이해 질문에서는 실체를 확인하기 전에 돌이라 고 생각하였다고 대답한 경우와 반창고가 들어있을 것이라고 생각하였다고 대답한 경우에 각각 1점을 주었다. 거짓 믿음 이 해에서는 실체를 아직 보지 않은 친구는 돌이라고 생각할 것 이라고 대답한 경우와 반창고가 들어있을 것이라고 생각할 것 이라고 응답한 경우에 각각 1 점을 주었다. 외양 실제 구분에서 
는 외양과 실제에 대한 두 질문 모두에 대해 정확히 대답하였 을 때에만(예: 반창고가 들어있을 것처럼 보이고, 실제로는 색 종이가 들어있다) 1 점을 주었다. 총 두 가지 물체가 사용되었 으므로, 표상 변화 이해, 거짓 믿음 이해, 그리고 외양 실제 구 분 점수는 각각 0-2점이 되었다.

\section{실제 교수활동의 교수의도 이해}

본 연구에서는 실제 교수활동의 예로서 새로운 동물의 이름 에 대해 가르쳐주기 위한 메모리 게임을 사용하였다. 일대일 로 게임을 진행하기에 앞서 각 유아에게 게임에 등장하는 '알 파카', '땅돼지'를 비롯한 일곱 개의 새로운 동물 사진을 보여 주며 알아보는 동물이 있는지 확인하였으나, 알아보는 경우는 없었다. 메모리 게임은 유아들에게 이미 익숙하거나 쉽게 배 울 수 있는 전형적인 방식으로 진행되었다. 동물 사진의 위치 를 잠시 기억한 후 사진이 보이지 않도록 뒤집은 다음, 연구자 와 유아가 차례를 돌아가며 같은 쌍의 사진이 나오도록 찾는 것이 규칙이었다. 기존의 메모리 게임과의 차이점은 새로운 동물 쌍이 나올 때마다 연구자가 동물의 이름을 두 번씩(예: “이 동물은 '알파카'야. '알파카.'”) 가르쳐주었다는 것이다.

먼저 유아들에게 동물 사진 카드를 사용하여 게임의 규칙 을 간단히 설명한 다음, 게임을 하는 의도에 대해 어떻게 기대 하는지 질문하였다(의도 기대 질문: "우리가 이 게임을 왜 하 는 것 같아? 새로운 동물에 대해 가르쳐주려고 하는 걸까, 아 니면 놀기 위해 하는 걸까?”). 이 질문 직후에 유아들은 무작위 로 통제집단과 실험집단으로 배정되었다. 통제집단에서는, 유 아들의 의도 기대에 대한 응답을 들은 후, "아. 그렇구나. 그럼 같이 게임을 해볼까?”라고 이야기 하면서 게임을 시작하였다. 반면, 실험집단에서는 의도 기대에 대한 유아의 응답을 들은 후, 연구자가 “이 게임을 하면서 새로운 동물의 이름을 가르쳐 줄게. 새로운 동물이 나올 때마다 그 동물 이름을 가르쳐줄게” 라고 교수의도를 안내하였다. 메모리 게임 자체는 실험집단과 통제집단 유아들에게 정확히 동일한 방식으로 진행되었다. 따 라서 두 집단 간의 유일한 차이점은 게임을 시작하기에 앞서 새로운 동물의 이름을 가르쳐주겠다는 교수의도에 대한 안내 를 들었는지의 여부였다. 게임을 한 후에는 게임을 한 의도를 어떻게 인식하는지 유아에게 질문하였다(의도 인식 질문: "우 리가 이 게임을 왜 한 것 같아? 새로운 동물의 이름을 가르쳐 주려고 한 것 같아? 아니면 놀기 위해서 한 것 같아?”).

게임의 의도 기대와 의도 인식에 대한 질문에서는 유아가 ‘새로운 동물(이름)에 대해 가르쳐주기 위해'라고 응답한 경우
에는 1 점, '놀기 위해’라고 응답한 경우에는 0 점으로 점수화하 였다.

\section{연구절차}

연구자의 소속기관 IRB 승인 이후, 유치원과 어린이집의 가정 통신문 배부를 통해 참여자를 모집하였다. 학부모가 동의서를 제출한 유아들을 대상으로 면접을 진행하였으며, 모든 측정 은 대학원에서 발달심리와 교육을 전공하는 연구자와 유아와 의 일대일 면접을 통해 이루어졌다. 면접은 기관 내의 빈 교실 에서 진행되었으며, 유아의 주의 집중 시간을 고려하여 2 회에 걸쳐 20 분 내의 면접을 통해 실시하였다. 또한 측정의 순서에 의한 효과를 배제하기 위해, 교수의도성 이해, 마음이론, 메모 리게임의 교수의도에 대한 측정 순서는 유아 간 역균형화되었 다. 양자택일 질문에서의 대안의 순서(예: “시연이가 숫자게임 을 왜 했을까? 재영이하고 놀고 싶어서 했을까? 아니면 숫자를 가르쳐주려고 하였을까?”) 역시 면접에서 무작위로 결정하여, 유아의 응답이 대안이 주어지는 순서에 의해 영향을 받지 않 도록 하였다.

\section{자료분석}

자료는 SPSS 22.0 (IBM Co., Armonk, NY) 프로그램을 사용하 여 분석하였다. 연령에 따른 교수의도성 이해수준 총점(10개 과제의 총점), 교수 상황과 모방 상황에서의 교수의도 이해 총 점은 각각 일원분산분석(ANOVA)을 통해 분석하였다. 교수의 도성 이해 과제 중 숨은 의도 게임과 숨은 의도 질문에서는 로 지스틱 회귀분석을 사용하여 연령에 따라 교수의도성 판단이 달라지는지 살펴보았다. 또한 교수의도성 이해, 실제 교수활 동(메모리 게임)의 교수의도에 대한 이해, 마음이론 간의 관계 는 Pearson 상관관계 또는 Spearman 상관관계를 통해 분석하였 다. 통제, 실험 집단에서 각각 교수의도성 이해수준과 유아의 연령이 게임의 교수의도에 대한 인식을 예측하는지에 대해서 는 로지스틱 회귀분석을 통해 살펴보았다.

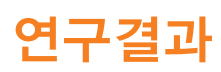

\section{유아들의 교수의도성 이해수준}

교수의도성 이해수준에 연령별 차이가 있는지 보기 위해 일 
Table 1

Understanding of Intentionality of Teaching by Age

\begin{tabular}{|c|c|c|c|}
\hline & 3-year-olds & 4-year-olds & 5-year-olds \\
\hline Successful teaching & $.68(S D=.48)$ & $.96(S D=.19)$ & $1.00(S D=.00)$ \\
\hline Unknown outcome teaching & $.61(S D=.50)$ & $.82(S D=.39)$ & $.97(S D=.18)$ \\
\hline Partially successful teaching & $.64(S D=.49)$ & $.86(S D=.36)$ & $.97(S D=.18)$ \\
\hline Failed teaching & $.50(S D=.51)$ & $.89(S D=.32)$ & $.97(S D=.18)$ \\
\hline \multirow[t]{2}{*}{ Total understanding of teaching stories } & $2.43(1.37)^{\mathrm{a}}$ & $3.54(.79)^{\mathrm{b}}$ & $3.90(.30)^{\mathrm{b}}$ \\
\hline & & $F=20.30^{* * *}, \mathrm{a}<\mathrm{b}$ & \\
\hline Successful imitation & $.64(S D=.49)$ & $.68(S D=.48)$ & $.84(S D=.37)$ \\
\hline Unknown outcome imitation & $.71(S D=.46)$ & $.71(S D=.46)$ & $.81(S D=.40)$ \\
\hline Partially successful imitation & $.82(S D=.39)$ & $.82(S D=.39)$ & $.77(S D=.43)$ \\
\hline Failed imitation & $.75(S D=.44)$ & $.82(S D=.39)$ & $.81(S D=.40)$ \\
\hline \multirow[t]{2}{*}{ Total understanding of imitation stories } & $2.93(1.30)^{\mathrm{a}}$ & $3.04(1.37)^{\mathrm{a}}$ & $3.23(1.31)^{\mathrm{a}}$ \\
\hline & & $F=.38$ & \\
\hline \multirow[t]{2}{*}{ Hidden intention game } & $.71(S D=.46)$ & $.82(S D=.39)$ & $.87(S D=.34)$ \\
\hline & & $\chi^{2}=2.29$ & \\
\hline \multirow[t]{2}{*}{ Hidden intention question } & $.36(S D=.49)$ & $.61(S D=.50)$ & $.65(S D=.49)$ \\
\hline & & $\chi^{2}=5.46$ & \\
\hline \multirow[t]{2}{*}{ Total understanding of intentionality of teaching } & $6.43(1.97)^{\mathrm{a}}$ & $8.00(1.72)^{b}$ & $8.65(1.50)^{\mathrm{b}}$ \\
\hline & & $F=12.57^{* * *}, \mathrm{a}<\mathrm{b}$ & \\
\hline
\end{tabular}

Note. $N=90$ (28 3-year-olds, 28 4-year-olds, 34 5-year-olds). Scheffé's contrasts were significant at the .001 level. *** $p<.001$.

원분산분석(ANOVA)을 실시한 결과, 교수의도성 이해 총점에 연령별 차이가 있었다 $(F=12.57, p<.001)$. Table 1 에서 알 수 있듯, Scheffé 사후분석 결과, 만 4세 $(M=8.00)$ 와 5세 $(M=8.65)$ 는 만 3세 $(M=6.43)$ 유아들보다 전반적으로 교수의도성을 잘 파악하는 것으로 나타났다. 이는, 연령이 증가할수록 학습결 과가 성공적이었는지 아니었는지 와는 무관하게 등장인물이 교수의도를 가지고 있었는지에 대해 더 정확하게 파악하게 되 고, 교수활동에 숨어있는 교수의도에 대해서도 더 잘 이해하 게 됨을 나타낸다. 이러한 교수의도성에 대한 이해의 발달은 만 3 세에서 4 세 사이에 주로 이루어지며, 만 4세와 5세의 이해 수준은 유사한 것으로 나타났다.

세부적으로 교수 상황과 모방 상황에서의 교수의도성 이해 에 연령별 차이가 있는지 역시 일원분산분석을 통해 각각 살 펴보았다. 그 결과, 교수 상황에서 교수의도를 파악하는 과업 에서는 연령에 따른 차이가 있었다 $(F=20.30, p<.001)$. Scheffé 사후분석 결과에 따르면, 만 3 세 $(M=2.43)$ 세보다는 만 4 세 $(M$ $=3.54)$ 와 만 5 세 $(M=3.90)$ 유아들이 높은 점수를 받았으며, 만 4세와 5 세는 유의하게 다르지 않았다. 한편, 모방 상황에서 의 교수의도성 판단에서는 연령에 따른 차이가 없었다. 따라
서 만 3세에서 4세 사이에 교수 상황에서 교수의도를 파악하 는 인지적 능력이 유의하게 발달하며, 모방상황에서의 교수의 도성 판단에는 별다른 연령별 차이가 없는 것으로 나타났다.

연령에 따라 숨은 의도 게임과 숨은 의도 질문 과업에서의 교수의도에 대한 이해가 달라지는지 역시 로지스틱 회귀분석 을 통해 살펴보았다. 그 결과, 두 과업 모두에서 연령에 따른 차이가 없는 것으로 나타났다. 숨은 의도 게임에서는 모든 연 령의 유아들이 게임 안에 지식을 가르치려는 의도가 담겨있다 는 것을 대체로 잘 이해하였으나, 숨은 의도 질문에서는 만 5 세 유아들도 유도 질문을 하는 의도가 지식을 가지고 있는지 확인하기 위한 것이라는 것을(지식을 얻기 위해서가 아니라) 잘 이해하지 못하였다.

교수의도성 이해 과업에서의 연령별 정확한 응답을 우연수 준의 확률(50\%)과 비교해 본 결과, 만 3세의 정확한 응답은 결 과 미상인 모방, 부분적 성공인 모방, 실패한 모방, 그리고 숨 겨진 게임 의도 과제에서 우연수준의 반응보다 유의하게 높았 다. 만 4 세 유아들의 교수의도성 판단은 성공적 모방과 숨은 의도 질문을 제외한 여덟 개의 과제에서 우연수준의 반응보다 유의하게 높았다. 만 5 세 유아들의 교수의도성 판단은 숨은 의 
Table 2

Correlations Between Theory of Mind and Understanding of Intentionality of Teaching

\begin{tabular}{|c|c|c|c|c|}
\hline & & $\begin{array}{c}\text { Representational } \\
\text { change }\end{array}$ & $\begin{array}{l}\text { False } \\
\text { belief }\end{array}$ & $\begin{array}{c}\text { Appearance-reality } \\
\text { distinction }\end{array}$ \\
\hline \multirow{3}{*}{$\begin{array}{l}\text { Understanding of } \\
\text { intentionality of teaching }\end{array}$} & Teaching stories & $.47^{* *}\left(.29^{* *}\right)$ & $.43^{* *}(.20)$ & $.17(.00)$ \\
\hline & Hidden intention game & $-.03 \quad(-.10)$ & $.17 \quad(.12)$ & $.01(-.03)$ \\
\hline & Hidden intention question & $.16 \quad(.06)$ & $.22^{*}(.12)$ & $.17(.102)$ \\
\hline
\end{tabular}

Note. $N=90$. Coefficients in parentheses are age-controlled correlations.

${ }^{*} p<.05 .{ }^{* *} p<.01$.

도 질문을 제외한 아홉 개의 과제에서 우연수준의 반응보다 높았다.

\section{교수의도성 이해와 마음이론의 관계}

유아들의 교수의도성 이해와 마음이론 간의 관계에 대해 Pearson 상관관계 분석을 통해 살펴보았다(Table 2). 유아들의 표상 변화 이해는 교수 상황에서의 교수의도성 이해 $(r=.47$, $p<.01)$, 모방상황에서의 교수의도성 이해 $(r=.25, p<.05)$, 그 리고 교수의도성 이해 총점 $(r=.47, p<.01)$ 과 관련이 있었으 며, 이 상관관계들은 연령에 의한 효과를 통제한 이후에도 유 지되었다(각각 $r=.29, p<.01 ; r=.22, p<.05 ; r=.32, p<.01$ ). 즉, 교수 또는 모방 상황에서 학습 결과와 무관하게 교수의도 가 있었는지를 정확하게 파악하는 능력은 특히 유아들의 표상 변화 이해 능력과 관련이 있는 것으로 나타났다. 한편, 유아들 의 거짓 믿음 이해 역시 교수 상황에서의 교수의도성 이해 $(r=$ $.43, p<.01)$, 숨은 의도 질문에서의 교수의도성 이해 $(r=.22, p$ $<.01)$, 교수의도성 이해 합계 $(r=.31, p<.01)$ 와 각각 상관이 있 었으나, 연령에 의한 효과를 통제한 이후에는 관계가 유의하 지 않았다. 종합하면, 유아들의 교수의도성 이해는 유아들의 마음이론, 특히 표상 변화에 대한 이해와 관련이 있는 것으로 나타났다.

\section{실제 교수활동의 교수의도에 대한 이해와 다른 변인간의 관계}

\author{
게임의 교수의도에 대한 이해와 마음이론, 교수 \\ 의도성 이해의 관계
}

메모리 게임을 하는 의도에 대한 기대와 인식이 유아의 마음
이론, 교수의도성 이해수준과 각각 관련이 있는지 보기 위해 Spearman 상관관계 분석을 실시하였다(Table 3). 상관관계 분 석에서는 이들 변수 사이에 전반적인 관계가 있는지 보기 위 해, 실험, 통제집단을 구분하지 않고 상관관계 분석을 실시하 였다.

게임 시작 전에 유아들이 갖는 교수의도에 대한 기대는, 모 방 상황에서의 교수의도성 이해 $(r=.29, p<.01)$, 숨은 의도 질 문의 교수의도 이해 $(r=.22, p<.01)$, 그리고 교수의도성 이해 총점 $(r=.35, p<.01)$ 과 각각 상관관계가 있었다. 특히, 게임 시 작 전의 교수의도에 대한 기대는 연령에 의한 효과를 통제한 후에도 교수의도성 이해 합계 $(r=.32, p<.01)$, 모방 상황에서 의 교수의도성 판단 $(r=.32, p<.01)$ 과 관련이 있었다. 게임 후 의 교수의도에 대한 유아들의 인식은 교수 상황에서의 교수의 도 이해 $(r=.30, p<.01)$, 숨은 의도 게임에서의 교수의도 이해 $(r=.26, p<.05)$, 그리고 교수의도성 이해 총점 $(r=.36, p<.01)$ 과 각각 상관관계가 있었다. 특히, 숨은 의도 게임에서의 교수 의도 이해와 교수의도성 이해 총점은 연령에 의한 효과를 통 제한 이후에도 메모리 게임의 교수의도에 대한 인식과 유의 한 상관이 있었다(각각 $r=.23, p<.05 ; r=.25, p<.05$ ). 종합하 면, 교수의도성 이해수준이 높을수록, 게임 전에 게임이 새로 운 동물에 대해 가르쳐주기 위한 활동일 것이라고 기대하고, 게임 후에도 활동이 동물 이름을 가르쳐주기 위한 것이었다고 인식하는 경우가 많았다.

한편, 마음이론 총점은 메모리 게임의 의도에 대한 기대와 유의한 상관관계가 있었으나 $(r=.23, p<.05)$, 연령에 의한 효 과를 통제한 이후에는 관련이 없었다. 또한 표상 변화 이해, 틀 린 믿음 이해, 그리고 외양 실제 구분 능력은 메모리 게임의 교 수의도에 대한 기대나 인식과 유의한 상관관계가 없었다. 따 라서 정신에 대한 일반적인 이해보다는, 교수의도성에 대한 이해가 실제 교수활동에 담긴 교수의도를 파악하는데 더 직접 
Table 3

Correlations Among Understanding of the Intention of the Memory Game, Understanding of Intentionality of Teaching, and Theory of Mind

\begin{tabular}{llcc}
\hline & & $\begin{array}{c}\text { Expectation of the intention } \\
\text { of the game }\end{array}$ & $\begin{array}{c}\text { Recognition of the intention } \\
\text { of the game }\end{array}$ \\
\hline $\begin{array}{l}\text { Understanding } \\
\text { of intentionality } \\
\text { of teaching }\end{array}$ & Teaching stories & .18 & $.30^{* *}$ \\
& Imitation stories & $(.05)$ & $.12)$ \\
& & $.219^{* *}$ & $(.15)$ \\
& Hidden intention game & $\left(.32^{* *}\right.$ & $.26^{*}$ \\
& & .10 & $\left(.23^{*}\right)$ \\
& Hidden intention question & $(.08)$ & .12 \\
& & $.22^{*}$ & $(.09)$ \\
& Total understanding of intentionality of teaching & $(.21)$ & $.36^{* *}$ \\
& & $.35^{* *}$ & $\left(.25^{*}\right)$ \\
& Representational change & $\left(.32^{* *}\right)$ & .05 \\
& & .20 & $(.10)$ \\
& False belief & $(.12)$ & .17 \\
& & .14 & $(.08)$ \\
& Appearance-reality distinction & $(.09)$ & .13 \\
& & .18 & $(.03)$ \\
& Total theory of mind & $(.15)$ & .15 \\
& & $.23^{*}$ & $(.03)$ \\
\hline
\end{tabular}

Note. Coefficients in parentheses are age-controlled correlations.

${ }^{*} p<.05 .{ }^{* *} p<.01$.

Table 4

Models Predicting Understanding of the Intention of the Memory Game

\begin{tabular}{|c|c|c|c|c|}
\hline & Variable & $B$ & Wald $\chi^{2}$ & OR \\
\hline \multirow[t]{4}{*}{ Control group } & Age & -.08 & .04 & .92 \\
\hline & Understanding of intentionality of teaching & $.42^{*}$ & 4.85 & 1.52 \\
\hline & Model $\chi_{2}$ & & $6.52^{*}$ & \\
\hline & Nagelkerke R2 & & .144 & \\
\hline \multirow[t]{4}{*}{ Experimental group } & Age & $.84^{*}$ & 3.44 & 2.32 \\
\hline & Understanding of intentionality of teaching & $.31^{*}$ & 3.14 & 1.36 \\
\hline & Model $\chi_{2}$ & & $10.331^{*}$ & \\
\hline & Nagelkerke R2 & & .231 & \\
\hline
\end{tabular}

${ }^{*} p<.05$.

적인 관련이 있는 것으로 나타났다.

통제, 실험집단에서의 게임의 교수의도에 대한

인식, 교수의도성 이해수준, 연령의 관계

통제집단과 실험집단에서 연령과 교수의도성 이해수준에 따 라 유아들이 게임을 한 의도를 다르게 인식하는지 보기 위해 각각 로지스틱 회귀분석을 실시하였다(Table 4). 먼저 새로운
동물 이름을 가르쳐주겠다는 교수의도에 대한 안내가 없었던 통제집단에 대해 살펴보았다. 이를 위해, 유아들의 연령과 교 수의도성 이해 총점을 게임의 교수의도에 대한 인식을 예측하 기 위한 모형에 동시에 투입하였다. 그 결과, 유아의 연령은 메 모리 게임의 교수의도에 대한 인식을 유의하게 예측하지 않았 지만, 교수의도성 이해 수준은 게임의 교수의도 인식을 유의 하게 예측하는 것으로 나타났다 $(B=.42, p<.05, \mathrm{OR}=1.52)$. 즉, 새로운 동물의 이름을 가르쳐주겠다는 교수 의도에 대한 
안내가 없었던 경우에는, 교수의도성에 대한 이해수준이 높을 수록 게임 후에 그 게임이 새로운 동물에 대해 가르쳐주기 위 한 것이었다고 인식하였다고 볼 수 있다.

실험집단에서도 연령과 교수의도성 이해수준에 따라 게임 의 교수의도에 대한 인식이 달라지는지 보기 위해 동일한 로 지스틱 회귀분석을 실시하였다. 그 결과, 유아의 연령 $(B=.84$, $p<.05, \mathrm{OR}=2.32)$ 과 교수의도성 이해수준 $(B=.31, p<.05$, $\mathrm{OR}=1.36)$ 모두가 유의하게 게임의 교수의도에 대한 인식을 예측하는 것으로 나타났다. 즉, 연령이 높을수록, 그리고 교수 의도성 이해수준이 높을수록 게임 이후에 그 게임이 새로운 동물에 대해 가르쳐주기 위한 것이었다고 인식하였다.

\section{논의 및 결론}

본 연구에서는 마음이론의 발달과 함께, 유아들이 교수 상황 에 담긴 교수의도에 대해 어떻게 이해하는지, 그리고 마음이 론과 교수의도성에 대한 이해의 발달이 실제 교수활동(메모 리 게임)의 교수의도에 대한 유아들의 이해와 관련이 있는지 에 대해 살펴보았다. 또한 메모리 게임의 교수의도에 대한 직 접적인 안내가 있는 상황과 없는 상황에서, 연령과 교수의도 성 이해 수준에 따라 교수의도에 대한 유아들의 인식이 달라 지는지에 대해서도 각각 살펴보았다. 연구 문제에 대한 결과 는 다음과 같다. 유아들은 연령이 증가할수록 교수 상황에 담 긴 교수의도에 대해 더 잘 판단하게 되었으며, 이러한 교수의 도성에 대한 이해의 발달은 유아들의 마음이론과 관련이 있었 다. 이러한 교수의도성에 대한 이해 수준이 높을수록 유아들 은 실제 교수활동이었던 메모리 게임의 교수의도에 대해서도 더 잘 예측하고 인식하였다. 또한, 메모리 게임의 교수의도에 대한 직접적인 안내가 없었던 경우에는, 교수의도성 이해 수 준이 높을수록 게임의 교수의도에 대해 더 잘 인식하는 편이 었으며, 게임의 교수의도에 대한 안내가 있었던 경우에는, 유 아의 연령과 교수의도성 모두 교수의도에 대한 인식을 유의하 게 예측하는 것으로 나타났다.

본 연구 결과는 연령이 증가함에 따라 유아들이 학습결과 에 관계없이 교수의도가 있는지의 유무에 대해 정확하게 판 단하게 되고, 활동에 숨겨진 교수의도에 대해서도 더 잘 파악 하게 된다는 것을 보여준다. 이러한 연령에 따른 교수의도성 에 대한 이해의 발달은 이스라엘(Ziv et al., 2008; 2016), 미국 Head start 프로그램(Cavadel \& Frye, 2017), 그리고 한국에서의 이전 연구(Yoon \& Kim, 2012)에서 보고된 결과와도 대체적으
로 일치한다.

그러나 세부 결과에서는 외국에서 진행된 이전 연구와의 차이점도 있었다. 이스라엘에서 진행된 Ziv 등(2008)의 연구 에서는 교수의도성에 대한 이해의 발달이 주로 4 세에서 5 세 사이에 나타났고, 만 3세와 4세 유아들의 이해수준에는 별다 른 차이가 없었다. 미국 Head Start 프로그램에서 진행된 연구 (Cavadel \& Frye, 2017)에서도, 저소득층 가정의 유아들을 대상 으로 하였기 때문에 직접적인 비교는 어렵지만, 만 4 세에서 5 세 사이에 교수에 대한 이해의 발달이 나타나는 것으로 나타 났다. 이에 비해, 본 연구에서는 교수의도성에 대한 이해의 발 달이 주로 만 3세에서 4 세 사이에 발생하고, 만 4세와 5세 사 이에서는 유의한 차이가 없는 것으로 나타났다. 이러한 경향 은 한국 유아들을 대상으로 했던 Yoon과 Kim (2012)의 이전 연 구 결과와도 일치한다. 또한 Ziv 등(2008)의 연구에서는 만 4 세유아들이 전체 10 개 중 5 개의 교수의도성 이해 과업에서 우 연수준 이상으로 교수의도성을 파악하였지만, 본 연구에서는 8 개의 과업에서 우연수준 이상으로 정확히 판단하였다. 이러 한 결과를 고려할 때, 한국 유아들의 교수의도성에 대한 이해 의 발달이 외국에 비해 다소 빠를 수 있다는 가능성에 대해 생 각해 볼만하다. 유아들이 이른 나이부터 한글, 수학, 영어, 예 체능 등의 다양한 영역에서 조기, 특기교육을 받는 한국적 상 황을 고려할 때(K. S. Lee, Chang, Chung, \& Hong, 2002; Kim $\& \mathrm{Ohm}, 2007)$, 빈번한 교수활동 경험이 교수의도성 이해 발 달을 가속화하였을 가능성에 대해 고려해 볼 수 있을 것이다. 이러한 가능성을 고려하여, 유아들의 교수활동 경험과 교수의 도성에 대한 이해 발달의 관계에 대해 후속연구에서 더 다루 어질 필요가 있다고 본다.

또한 본 연구 결과는 영아기에 나타나는 타인의 의도에 대 한 암시적(implicit) 이해 발달이, 유아기에 이르러 교수의도 성에 대한 분명한 이해로 발전함을 보여준다(Jeong \& Frye, 2018). 영아들을 대상으로 한 선행 연구들은 3 세 이전의 영 아들이 타인의 의도에 대해 추론할 수 있으며, 이러한 추론 이 타인의 행동에 대한 모방이나(Behne, Carpenter, Call, \& Tomasello, 2005; Meltzoff, 1995) 언어 학습(Baldwin, 1991, 1993)에 영향을 미친다는 것을 보여주었다. 예를 들어, 16-19 개월 영아들은 성인이 단어를 말할 때 어떤 사물을 주시하는 지에 대해 주목하고, 그 단어가 그 사물을 지칭한다는 것을 이 해하였다(Baldwin, 1991, 1993). 이러한 학습은 무엇을 지칭하 고자 하는지에 대한 타인의 의도에 대해 암시적으로 이해할 수 있을 때 가능하다. 그러나 Moses (2001)에 따르면, 영아기 에 나타나는 타인의 의도에 대한 이해는, 성인의 이해와는 달 
리, 동기적 측면(motivational aspect)만을 고려한다. 즉, 영아들 은 바람(desire)과 의도를 구분하지 않기 때문에, 원했기 때문 에 그 행동을 하였다고 이해한다는 것이다. 단순히 바람에 근 거한 이해에서 벗어나, 의도를 현상이나 결과와 분리하여 이 해하기 위해서는 더 많은 이해와 성숙이 필요할 수 있다. 예를 들어, 실패한 교수 상황에 대한 과업에서 학습 결과는 성공적 이지 않았으나 교수자가 상대방을 가르치려고 하였다는 것을 이해하기 위해서는, 결과와 의도를 분리하여 사고할 수 있어 야 한다. 이러한 교수의도에 대한 명확한 이해는 유아기에 이 르러 나타나는 것으로 보인다.

교수의도성에 대한 이해의 발달은 마음이론의 발달과 유의 한 관계가 있었다. 이러한 결과는 유아들의 교수 상황에 대한 이해가 마음이론과 이론적으로(Olson \& Bruner, 1996), 그리고 실증적으로(Davis-Unger \& Carlson, 2008; Strauss et al., 2002; Ziv \& Frye, 2004; Ziv et al., 2008) 밀접한 관련이 있다는 것을 보여준 이전 연구들과도 맥을 같이 한다. 특히, 본 연구에서는 유아들의 표상 변화나 거짓 믿음에 대한 이해가 유아들의 교 수의도성 이해와 관련이 있었으며, 표상 변화에 대한 이해는 연령에 의한 효과를 통제한 이후에도 교수의도성 이해와 유의 한 관계가 있었다. 유아들이 표상 변화 과업을 잘 수행하기 위 해서는, 사물의 실체를 확인 한 후 본인의 믿음 또는 지식이 변 하였음을 인식해야 한다(Gopnik \& Astington, 1988). 이것은 타인에게 뭔가를 배운 이후 학습자의 지식이나, 기술, 이해 등 이 변화하는 상황과 유사할 수 있다. 따라서 마음이론의 여러 영역들 중에서도 믿음 또는 지식의 변화를 감지하고 이해하는 표상 변화에 대한 이해가 교수에 대한 이해의 발달과 개념적 으로 관련이 있을 수 있다.

이러한 교수의도성에 대한 전반적인 이해의 발달은 유아들 이 실제 교수활동의 교수의도에 대해 어떻게 기대하고 인식하 는지와 관련이 있었다. 교수의도성 이해수준이 높을수록 유아 들은 메모리 게임이 단순히 놀기 위한 것이 아니라 새로운 동 물에 대해 가르쳐주기 위한 것이라고 기대하였다. 또한 교수 의도성 이해수준이 높을수록 게임 이후에도 새로운 동물에 대 해 가르쳐주기 위해 게임을 한 것이라고 인식하였다. 이러한 관계는 연령에 의한 효과를 통제한 이후에도 유지되었다.

이러한 교수의도성에 대한 이해수준과 실제 교수활동의 교 수의도에 대한 인식의 관계는 통제집단과 실험집단을 나누어 살펴보았을 때에도 각각 유의하였다. 메모리 게임에 담긴 교 수의도에 대한 안내를 듣지 않았던 통제집단에서, 교수의도성 이해 수준이 높은 유아들은 게임 후에 게임을 한 이유가 새로 운 동물에 대해 가르쳐주기 위해서였다고 인식하는 양상을 보
였다. 통제집단에서 유아의 연령은 유아가 메모리 게임의 교 수의도를 어떻게 인식하는지와 유의한 관계가 없었다. 따라서 활동의 교수의도에 대한 안내가 없는 상황에서는, 연령보다 상황의 교수의도를 정확히 판단하는 인지능력이 실제 활동의 교수의도를 파악하는데 더 중요한 역할을 했다고 볼 수 있다.

한편 메모리 게임의 교수의도에 대한 안내가 있었던 실험 집단에서는, 연령과 교수의도성 이해 수준 모두가 게임의 교 수의도에 대한 인식을 예측하는 것으로 나타났다. 즉, 연령이 높을수록, 그리고 교수의도성에 대한 이해수준이 높을수록 유 아들이 메모리 게임의 의도가 새로운 동물 이름에 대해 가르 쳐주기 위해서였다고 인식하였다. 실험집단의 모든 유아들이 새로운 동물 이름에 대해 가르쳐주겠다는 설명을 들었음에도 불구하고, 연령과 교수의도성 이해 수준에 따라 이를 받아들 이는 정도가 달랐다는 점은 주목할 만한 부분이다. 실험집단 에서 게임의 교수의도가 놀기 위함이었다고 응답한 이유가 단 순히 “게임을 하면서 새로운 동물 이름을 가르쳐줄게”라는 연 구자의 설명을 잊어버렸기 때문이라고 보기는 어렵다. 그 이 유는 연구자가 교수의도에 대한 질문을 할 때, "우리가 이 게 임을 왜 한 것 같아? 새로운 동물 에 대해 가르쳐주려고 한 것 같아? 아니면 놀기 위해 한 것 같아?”라고 질문하면서 동물에 대해 가르쳐주려는 교수의도가 있었을 수 있다는 가능성을 다 시 언급해주었기 때문이다. 따라서 유아들이 외부로부터 주어 지는 지식이나 설명을 그대로 받아들이는 것이 아니라, 본인 들의 고유의 관점에 기반을 두고 이해를 형성해 나간다는 것 을 고려할 때(Olson \& Bruner, 1996), 유아들의 교수활동에 대 한 인식 역시, 유아들의 연령과 발달에 따라 달라진다는 것을 알 수 있다.

더불어 실험집단에서 교수의도성 이해수준뿐만 아니라 연 령이 메모리 게임의 교수의도에 대한 인식을 유의하게 예측 하였다는 결과에 대해서는 몇 가지 해석이 가능하다. 실험집 단에서는 새로운 동물의 이름에 대해 가르쳐줄 것이라는 설 명을 듣고 게임을 시작하였기 때문에, 연구자의 언어적 설명 이나 안내에 대한 이해능력이 게임의 교수의도에 대한 판단 에 영향을 주었을 수 있다. 일반적으로 연령이 증가할수록 유 아들의 언어 이해능력 역시 향상되기 때문에(Baumwell, TamisLeMonda, \& Bornstein, 1997; B.-J. Lee, Kim, \& Kim, 2010), 이 러한 언어능력이 연령에 의한 효과로 나타났을 가능성이 있 다. 또는 연령이 증가할수록 교수활동에 대한 경험이 쌓이기 마련이므로, 이러한 경험이 메모리 게임의 의도에 대한 인식 에 영향을 주었을 수도 있다. 따라서 언어 능력을 비롯한 다른 변인들을 고려하여 유아들의 교수활동에 대한 인식을 살펴본 
다면 더 정확한 해석이 가능할 것이다.

유아들의 교수 상황에 대한 이해에 대해 다룬 본 연구는 기 존의 마음이론에 대한 연구들이 주목하지 않았던 새로운 영 역과 그에 대한 접근 방향에 대해 제시한다. 기존의 연구들 은 마음이론의 발달이 유아들의 사회적 능력이나 사회적 행 동(Chung, 2009; Oh, 2013), 언어사용(Song, 2004; N. Shin \& $\mathrm{Kim}, 2016)$, 그리고 놀이 행동과 경향(Park, 2006; E.-S. Shin, $2005)$ 등과 관련이 있음을 보여주었다. 이러한 연구들은 대체 로 마음이론의 발달이 사회적 상황이나 타인의 행동에 대한 이해, 긍정적인 사회적 행동과 놀이 행동과 관련이 있음을 보 고하였다. 본 연구의 결과는, 마음이론이 지식을 가르치고 배 우는 사회적 상황에 대한 이해에도 적용될 수 있음을 시사해 준다.

이러한 교수와 학습 상황에 대한 이해는 유아들의 학업능 력과 학교 준비도에도 중요한 영향을 줄 수 있다(Cavadel \& Frye, 2017; Ziv et al., 2008). 최근 연구에서 교수의도성에 대한 판단을 비롯한 교수활동에 대한 이해능력은, 마음이론과 더불 어 유아의 문해능력과 수학능력을 유의하게 예측하는 것으로 나타났다(Cavadel \& Frye, 2017). 나아가 교수활동에 대한 유아 의 이해 수준은 1 년 후의 문해능력을 예측하기도 하였다. 이러 한 횡단적, 종단적 결과를 고려할 때, 후속 연구에서는 마음이 론과 교수 상황에 대한 이해가 유아의 교육활동에 대한 참여 나 실제 학습에 어떻게 영향을 주는지에 대해 구체적으로 살 펴볼 필요가 있다.

또한 본 연구에서는 교수의도성에 대한 이해가 실제 교수 활동에 대한 이해에 어떻게 적용되는지 보기 위해, 메모리 게 임을 한 의도에 대해 유아들이 어떻게 이해하는지에 대해 살 펴보았다. 하지만 후속 연구에서는 좀 더 다양한 영역에서 교 수활동에 대한 이해가 어떻게 적용이 되는지에 대해 살펴볼 필요가 있을 것이다. 예를 들어, 교수의도에 대한 이해가 높으 면 활동에 대한 긍정적인 참여가 증가하는지, 그리고 실제로 학습이 증가하는지에 대해 살펴볼 필요가 있다. 또한, 본 연구 에서는 유아들의 언어능력을 고려하여, 메모리 게임을 한 의 도에 대해 양자택일의 방식을 사용하여 질문하였다. 하지만 양자택일과 열린 질문을 모두 사용하여 살펴보면, 유아들이 교수활동에 대해 어떻게 인식하는지에 대해 보다 종합적으로 이해할 수 있을 것이다.

더불어, 좀 더 다양한 형태의 교수활동으로 연구 주제를 확 장할 필요가 있다. 본 연구에서는 연구자가 교수의도를 명시 적으로 밝히지 않는 한, 그 교수의도가 뚜렷하게 드러나지 않 는 메모리 게임을 사용하였다. 하지만 교수의도가 좀 더 분명
히 드러날 수 있는 이야기 나누기와 같은 활동에서는 유아들 의 교수 상황에 대한 인식이 다를 수 있을 것이다. 또한, 학문 적 지식을 교환하는 활동에 대한 유아들의 인식은 신체, 음악, 체육 영역의 교수활동에 대한 인식과 다를 수 있다. 좀 더 다양 한 교수활동 속에서 유아들이 무엇을 배운다고 인지하는지, 그리고 유아들의 인식이 교수활동을 준비한 성인의 계획과 일 치하는지 살펴본다면, 교육활동을 계획하고 운영하는데 실질 적인 도움이 될 수 있을 것이다.

유아들은 다양한 교수활동으로부터 지식과 기술, 태도 등 을 배운다(Strauss et al., 2002). 유아들이 교수활동에 대해 어떻 게 인식하고 참여하며, 이러한 인식이 학습에 어떻게 영향을 주는지에 대한 연구는 유아들의 시각에서 교육활동을 이해하 는데 도움이 될 수 있다. 나아가 유아의 연령과 발달을 고려하 여, 교수활동을 어떻게 설계할 수 있는지에 대한 판단에도 기 여할 수 있을 것이다.

\section{Conflict of Interest}

No potential conflict of interest relevant to this article was reported.

\section{References}

\section{In English}

Baldwin, D. A. (1991). Infants' contribution to the achievement of joint reference. Child Development, 62(5), 875-890. doi: $10.2307 / 1131140$

Baldwin, D. A. (1993). Early referential understanding: Infants' ability to recognize referential acts for what they are. Developmental Psychology, 29(5), 832-843. doi:10.1037/0012-1649.29.5.832

Baumwell, L., Tamis-LeMonda, C. S., \& Bornstein, M. H. (1997). Maternal verbal sensitivity and child language comprehension. Infant Behavior and Development, 20(2), $247-$ 258. doi:10.1016/S0163-6383(97)90026-6

Behne, T., Carpenter, M., Call, J., \& Tomasello, M. (2005). Unwilling versus unable: Infants' understanding of intentional action. Developmental Psychology, 41(2), 328-337. doi:10.1037/0012-1649.41.2.328

Cavadel, E. W., \& Frye, D. A. (2017). Not just numeracy and literacy: Theory of mind development and school readiness among low-income children. Developmental Psychology, 53(12), 2290-2303. doi:10.1037/dev0000409 
Davis-Unger, A. C., \& Carlson, S. M. (2008). Development of teaching skills and relations to theory of mind in preschoolers. Journal of Cognition and Development, 9(1), 26-45. doi:10.1080/15248370701836584

Flavell, J. H. (2004). Theory-of-mind development: Retrospect and prospect. Merrill-Palmer Quarterly, 50(3), 274-290. doi:10.1353/mpq.2004.0018

Frye, D., \& Ziv, M. (2005). Teaching and learning as intentional activities. In B. D. Homer \& C. S. Tamis-LeMonda (Eds.), The development of social cognition and communication (pp. 231-258). Mahwah, NJ: Lawrence Erlbaum Associates Publishers.

Gopnik, A., \& Astington, J. W. (1988). Children's understanding of representational change and its relation to the understanding of false belief and the appearance-reality distinction. Child Development, 59(1), 26-37. doi:10.2307/1130386

Jeong, J., \& Frye, D. (2018). Explicit versus implicit understanding of teaching: Does knowing what teaching is help children to learn from it? Teaching and Teacher Education, 71, 355365. doi:10.1016/j.tate.2018.02.002

Meltzoff, A. N. (1995). Understanding the intentions of others: Re-enactment of intended acts by 18-month-old children. Developmental Psychology, 31(5), 838-850. doi:10.1037/00121649.31.5.838

Moses, L. J. (2001). Some thoughts on ascribing complex intentional concepts to young children. In B. F. Malle, L. J. Moses, \& D. A. Baldwin (Eds.), Intentions and intentionality: Foundations of social cognition (pp. 69-84). Cambridge, MA: MIT Press.

Olson, D. R., \& Bruner, J. (1996). Folk psychology and folk pedagogy. In D. R. Olson \& N. Torrance (Eds.), Handbook of education and human development (pp. 9-27). Cambridge, MA: Blackwell.

Skerry, A. E., Lambert, E., Powell, L. J., \& McAuliffe, K. (2013). The origins of pedagogy: Developmental and evolutionary perspectives. Evolutionary Psychology, 11(3), 550-572. doi:10.1177/147470491301100306

Strauss, S., Ziv, M., \& Stein, A. (2002). Teaching as a natural cognition and its relation to preschoolers' developing theory of mind. Cognitive Development, 17(3-4), 14731787. doi:10.1016/S0885-2014(02)00128-4

Kruger, A., \& Tomasello, M. (1996). Cultural learning and learning culture. In D. Olson, \& N. Torrance (Eds.). The handbook of education and human development: New models of teaching, learning, and schooling (pp. 369-387). Oxford: Blackwell.

Ziv, M., \& Frye, D. (2004). Children's understanding of teaching: The role of knowledge and belief. Cognitive Development, 19(4), 457-477. doi:10.1016/j.cogdev.2004.09.002

Ziv, M., Solomon, A., \& Frye, D. (2008). Young children's recognition of the intentionality of teaching. Child Development, 79(5),
1237-1256. doi:10.1111/j.1467-8624.2008.01186.x

Ziv, M., Solomon, A., Strauss, S., \& Frye, D. (2016). Relations Between the development of teaching and theory of mind in early childhood. Journal of Cognition and Development, 17(2), 264-284. doi:10.1080/15248372.2015.1048862

\section{In Korean}

Chung, D.-H. (2009). Theory of mind and social relationships of 4 or 5 Year-Old Children. Early Childhood Education Research \& Review, 13(3), 31-50.

Kim, B. R., \& Ohm, J. A. (2007). Relationship between the actual state of extra curricula education for kindergarteners and maternal beliefs regarding child rearing. Family and Environment Research, 45(8), 13-24.

Oh, S.-Y. (2013). The relationship between young children's development of theory of mind and their adjustment in early childhood education institutions. Journal of Children's Literature and Education, 14(4), 631-650.

Park, S. (2006). Children's theory of mind and play script in social pretend play. Korean Journal of Early Childhood Education, 26(5), 145-171.

Song, Y.-J. (2004). Children's theory of mind : Story constructions compared with social behavior explanations, Korean Journal of Child Studies, 25(4), 147-162.

Shin, E.-S. (2005). Relationships among theory of mind, decontexutlization in pretend play, language, executive function, and central coherence in young children. Korean Journal of Early Childhood Education, 25(1), 65-90.

Shin, N., \& Kim, S. (2016). Relations between mothers' and Preschoolers' use of mental state terms during pretend play and preschoolers' mental state terms in hypothetical narratives. Korean Journal of Child Studies, 37(2), 127-142. doi:10.5723/ kjcs.2016.37.2.127

Lee, B.-J., Kim, N.-H., \& Kim, H.-M. (2010). The effect of an improvement service for child cognitive ability aimed at the development of linguistic ability in children between the ages of 3-6 years: An evaluation for short-term effectiveness. Korean Journal of Child Studies, 31(6), 107-123.

Lee, H. (2011). Relations among teaching, false belief, vocabulary and school readiness. The Korean Journal of Developmental Psychology, 24(2), 87-102.

Lee, K. S., Chang, Y. H., Chung, M. R., \& Hong, Y. H. (2002). Parents' perception and the current state of very early education at home. Korean Journal of Early Childhood Education, 22(3), 153-171.

Yoon, B.-H., \& Kim, H.-J. (2012). Correlations among perspective taking, theory of mind, recognition of the teaching intention, reaction of teaching and learning in young children. Korean Journal of Early Childhood Education, 32(1), 275-298. 
ORCID

Received March 2, 2018

Revision received May 29, 2018

Jeein Jeong https://orcid.org/0000-0002-5130-4624 